Tersedia Online: http://journal.unj.ac.id/unj/index.php/ipensil

\title{
PENGAPLIKASIAN AUGMEN'TED REALITY PADA MODUL PEMBELAJARAN MENGGAMBAR TEKNIK 2 DAN CAD DI PROGRAM STUDI PENDIDIKAN TEKNIK BANGUNAN, FAKULTAS TEKNIK, UNIVERSITAS NEGERI JAKARTA
}

\author{
Kaka Sumarna, ${ }^{1}$ Arris Maulana², Doddy Rochadi ${ }^{3}$ \\ 1,2,3 Universitas Negeri Jakarta \\ 1umarnakaka@gmail.com ${ }^{2}$ arrismaulana@,unj.ac.id, ${ }^{3}$ drohadi@,unj.ac.id
}

\author{
Diterima : 28 Agustus 2019 \\ Direvisi : 15 September 2019 \\ Diterbitkan : 21 September 2019 \\ DOI $\quad: 10.21009 /$ jpensil.v8i2.11956
}

\section{Abstract}

The purpose of this study is to apply Augmented Reality to the Drawing Engineering Learning Module 2 and $C A D$. This research is included in Research and Development (R\&D) with the Thiagarajan development research model. The steps of research and development are abbreviated as 4D, namely Define, Design, Development and Dissemination. This research used instrument data collection technique, namely questionnaire. The questionnaire was given to material experts and media experts to test the feasibility of instructional media products. The results of the feasibility of learning media products in the form of learning modules and Augmented Reality applications, named ARCAD3D, are as follows: a) the material assessment by the material experts received a value of $81.8182 \%$ with a very good interpretation; b) media assessment by media experts gets a value of $85.6 \%$ with very good interpretation. Based on the results of the feasibility, it can be concluded that Augmented Reality is very feasible to be applied in the Drawing Technique 2 and CAD learning modules that can help students improve their imagination to draw techniques and can be used by lecturers and students in learning.

Keywords: Augmented Reality, Learning Media, Learning Modules

\section{Pendahuluan}

Saat ini, dunia tengah memasuki era Revolusi Industri 4.0 atau Revolusi Industri Dunia Ke-Empat dimana teknologi telah menjadi basis dalam kehidupan manusia. Segala hal menjadi tanpa batas dan tidak terbatas akibat perkembangan internet dan teknologi digital. Era ini telah mempengaruhi banyak aspek kehidupan baik di bidang ekonomi, politik, kebudayaan, seni, dan bahkan sampai ke dunia pendidikan (Nasir, 2018 ).

Hubungan dunia pendidikan dengan Revolusi Industri 4.0 adalah dunia pendidikan dituntut harus mengikuti perkembangan teknologi yang sedang berkembang pesat serta memanfaatkan teknologi informasi dan komunikasi sebagai fasilitas lebih dan serba canggih untuk memperlancar proses pembelajaran.

Mahasiswa Program Studi Pendidikan Teknik Bangunan merupakan lulusan dari Sekolah Menengah Atas (SMA)/Sekolah Menengah Kejuruan (SMK)/MA dan sederajat yang memiliki karakteristik yang bermacam-macam. Keahlian yang mereka miliki sangat diperlukan saat mereka mengemban ilmu di perguruan tinggi. Salah satu keahlian yang harus dimiliki saat mengemban ilmu di perguruan tinggi khususnya pada Program Studi Pendidikan Teknik Bangunan Fakultas Teknik Universitas Negeri Jakarta adalah kemampuan menggambar teknik. Menggambar teknik merupakan 
kemampuan menggambar dengan mengikuti kaidah-kaidah tertentu yang telah di sepakati (Budi, 2016, pp.111-112).

Menggambar teknik dapat dilakukan secara manual atau menggunakan teknologi. Menggambar teknik secara manual yaitu menggunakan kertas dan seperangkat alat gambar lainnya. Sedangkan dengan teknologi, yakni menggunakan sebuah software untuk menggambar teknik diantaranya yaitu AutoCAD, Revit, Google SketchUp, 3D Max dan lain-lain. Bagi mahasiswa lulusan SMA/SMK/MA dan sederajat keahlian menggambar teknik mungkin kurang dikuasai dengan baik, hal ini yang menyebabkan mereka merasa kesulitan saat mengikuti proses pembelajaran menggambar teknik di kelas. Berbeda dengan mahasiswa lulusan SMK Bangunan, mereka sudah dibekali dengan keahlian menggambar teknik sejak kelas 10 hingga kelas 12, yang dapat memudahkan mereka saat mengikuti pembelajaran menggambar teknik di kelas.

Kata "media" berasal dari bahasa Latin "medium" yang berarti "perantara" atau "pengantar". Lebih lanjut, media merupakan sarana penyalur pesan atau informasi belajar yang hendak disampaikan oleh sumber pesan kepada sasaran atau penerima pesan tersebut. ( Rusdi Susilana \& Cepi Riyana, 2010).

Azhar (2012: .p.6), mendefinisikan media pembelajaran adalah setiap orang, bahan, alat, atau peristiwa yang dapat menciptakan kondisi yang memungkinkan pembelajar untuk menerima pengetahuan, keterampilan dan sikap. Dengan pengertian itu, maka guru atau dosen, buku ajar, serta lingkungan adalah media.

Pada pembelajaran Menggambar Teknik 2 dan CAD teknologi yang digunakan yaitu software dan komputer karena pada mata kuliah ini dituntut untuk menggunakan perangkat tersebut. Pembelajaran di awali dengan membuat gambar teknik dengan bentuk dua dimensi. Setelah itu dilanjutkan dengan menggambar teknik dengan bentuk tiga dimensi. Perangkat software yang digunakan untuk membuat gambar dua dan tiga dimensi adalah AutoCAD. AutoCAD adalah program komputer desain grafis yang menyediakan fasilitas untuk membuat gambar teknik yang lengkap dalam bentuk dua dan tiga dimensi. Sesuai dengan perkembangan teknologi khususnya komputer, semakin banyak programprogram aplikasi AutoCAD yang diperuntukan bagi masyarakat umum atau khusus untuk kalangan industri seperti ArchiCAD, 3D Max, 3D Homs Design, Piping Drawing dan sebagainya (Hasanudin, 2011).

Dalam kegiatan pembelajaran Menggambar Teknik 2 dan CAD untuk membuat gambar tiga dimensi sebuah objek dapat menggunakan aplikasi lain seperti Google SketchUp. Google SketchUp merupakan salah satu dari sekian banyak software yang berfungsi untuk membuat gambar tiga dimensi. Google SketchUp dapat digunakan oleh praktisipraktisi di bidang arsitektur, sipil, pembuatan film, pengembang game, desainer grafis, bahkan ilustrator untuk menciptakan gambar tiga dimensi sesuai kebutuhan.

Pada saat menggambar teknik, khususnya saat menggambar sebuah objek tiga dimensi, diperlukan daya imajinasi yang tinggi. Imajinasi diperlukan untuk membayangkan objek seperti apa yang akan digambar secara manual atau menggunakan software komputer. Untuk membantu mahasiswa dalam membayangkan sebuah objek yang akan digambar, perlu adanya sebuah pemabruan teknologi yang digunakan pada saat proses pembelajaran.

Salah satu teknologi yang dapat digunakan untuk membantu mahasiswa dalam meningkatkan daya imajinasi tersebut yaitu teknologi Augmented Reality (AR). Secara sederhana Augmented Reality (AR) adalah penggabungan antara benda virtual dan benda nyata secara alami melalui sebuah proses komputeristik, seolah-olah terlihat real seperti ada dihadapan pengguna. Augmented Reality 
(AR) atau realitas bertambah, adalah teknologi yang menggabungkan benda maya tiga dimensi (3D) kedalam sebuah lingkungan nyata tiga dimensi dan menampilkannya dalam waktu nyata. Tidak seperti realitas maya (virtual reality) yang sepenuhnya menggantikan kenyataan, realitas tertambah sekedar menambahkan atau melengkapi kenyataan (Robot, 2014).

Augmented Reality memberikan gambaran kepada pengguna tentang penggabungan dunia nyata dengan dunia maya dilihat dari tempat yang sama. Augmented Reality memiliki tiga karakteristik yaitu bersifat interaktif (meningkatkan interaksi dan persepsi pengguna dengan dunia nyata), menurut waktu nyata (real time) dan berbentuk 3 dimensi.

Dalam proses pembelajaran

Menggambar Teknik 2 dan CAD mahasiswa dibekali dengan sebuah modul yang memuat materi-materi mengenai gambar dua dimensi dan tiga dimensi. Kelebihan dari modul ini adalah modul dikemas menarik dan praktis.

Modul pembelajaran adalah satuan program belajar yang terkecil yang dapat dipelajari oleh peserta didik sendiri secara perseorangan atau diajarkan oleh peserta didik kepada dirinya sendiri "selfinstructional". Sedangkan menurut (Dr. Purwanto, M.Pd :2010:7) modul pembelajaran merupakan bahan ajar yang disusun secara sistematis dan menarik dimana didalam modul pembelajaran tersebut mencakup isi materi, metode dan evaluasi yang dapat digunakan secara mandiri (belajar sendiri) untuk dapat mencapai kompetensi yang diharapkan secara mandiri. Berdasarkan pengertian modul pembelajaran yang telah diutarakan oleh ahli di atas maka penulis menyimpulkan bahwa modul pembelajaran adalah salah satu bentuk bahan ajar cetak yang memiliki sifat "self- instructional" dimana didalam modul tersebut memuat suatu konsep yang mencakup seluruh materi yang akan dipelajari, metode yang digunakan dalam proses pembelajaran dan evaluasi yang dapat memberikan penilaian dari hasil pembelajaran. Selain itu modul pembelajaran dapat digunakan secara mandiri dan dikemas secara sistematis agar dapat membuat modul tersebut terlihat menarik sehingga dapat menarik minat peserta didik untuk belajar.

Objek tiga dimensi (3D) adalah sebuah benda/ruang yang memiliki panjang, lebar dan. tinggi yang memiliki bentuk. 3D tidak hanya digunakan dalam matematika dan fisika saja melainkan dibidang grafis, seni, animasi, komputer dan lain - lain. Konsep tiga dimensi atau 3D menunjukkan sebuah objek atau ruang memiliki tiga dimensi geometris yang terdiri dari: kedalaman, lebar dan tinggi. Contoh tiga dimensi suatu objek / benda adalah bola, piramida atau benda spasial seperti kotak sepatu. Istilah "3D" juga digunakan untuk menunjukkan representasi dalam grafis komputer (digital), dengan cara menghilangkan gambar stereoscopic atau gambar lain dalam pemberian bantuan, dan bahkan efek stereo sederhana, yang secara konstruksi membuat efek 2D (dalam perhitungan proyeksi perspektif, shading).

Ponsel pintar (Smartphone) adalah telepon genggam yang mempunyai kemampuan dengan pengunaan dan fungsi yang menyerupai komputer dan contoh manfaat smartphone dari sisi software adalah tersedianya layanan akses data. Layanan ini dapat dimanfaatkan oleh setiap Smartphone untuk memungkinkan penggunanya terhubung dengan konektivitas internet setiap saat dimanapun mereka berada. Layanan akses data pada Smartphone adalah bermanfaat untuk keperluan browsing, Email, Chating hingga posting ( Nurcahya Agung Sulistya Budi (2015).

Sistem Operasi Android merupakan salah satu sistem operasi mobile populer yang di ciptakan oleh perusahaan Google. Pengertian Sistem Operasi Android sendiri secara singkat adalah sebuah sistem operasi berbasis linux yang di peruntukkan untuk telepon seluler (Smartphone) (Shukla Anupam (2012)). Kelebihan sistem operasi Android sendiri ialah menyediakan platfrom terbuka (open source) bagi para 
pengembang untuk menciptakan berbagai jutaan aplikasi mereka sendiri yang nanti nya akan dipergunakan untuk berbagai macam peranti bergerak (mobile devices).

Teknologi Augmented Reality (AR) akan diterapkan pada modul pembelajaran Menggambar Teknik 2 dan CAD untuk menampilkan gambar-gambar tiga dimensi. Kelebihan dari teknologi ini adalah teknologi ini bersifat interaktif dan mudah digunakan serta pemanfaatannya sesuai dengan tuntutan pendidikan Era Revolusi Industri 4.0 yang menuntut pendidikan harus disertai dengan teknologi terdepan. Dengan menggunakan teknologi ini mahasiswa dapat melihat objek tiga dimensi tidak perlu menggunakan laptop yakni dapat menggunakan smartphone yang telah terinstall sebuah aplikasi Augmented Reality (AR).

Berdasarkan dari berbagai paparan di atas, peneliti ingin mengaplikasikan teknologi Augmented Reality (AR) ke dalam sebuah modul pembelajaran Menggambar Teknik 2 dan CAD. Berdasarkan hasil analisa kebutuhan awal, 98,4\% mahasiswa yang mengisi kuisioner menyatakan setuju apabila dikembangkan sebuah modul pembelajaran Menggambar Teknik 2 dan CAD berbasis Augmented Reality (AR). Melalui penelitian yang berjudul "Pengaplikasian Augmented Reality Pada Modul Pembelajaran Menggambar Teknik 2 dan CAD " dengan harapan pembelajaran menjadi lebih menarik dan sesuai dengan tujuan pembelajaran. Tujuan dari penelitian ini adalah untuk mengaplikasikan Augmented Reality pada Modul Pembelajaran Menggambar Teknik 2 dan CAD. Penelitian ini dapat memberikan manfaat sebagai berikut penelitian ini dapat memberikan konstribusi dan konsep baru dalam perkembangan ilmu pendidikan, pengetahuan dan teknologi. Hasil penelitian ini dapat digunakan sebagai bahan acuan dan pertimbangan bagi peneliti selanjutnya Bagi mahasiswa sebagai penerapan dan bekal pengalaman ilmu pengetahuan yang sudah didapat baik di bangku kuliah maupun di lingkungan masyarakat. Bagi pengguna/pendidik dapat mempermudah dalam menyampaikan materi dalam proses pembelajaran. Bagi mahasiswa akan mempermudah dalam melakukan pembelajaran secara mandiri karena lebih praktis. Bagi lulusan yang akan memilih profesi menjadi guru akan membuat suasana pembelajaran menjadi lebih interatif dan menyenangkan.

\section{Metode Penelitian}

Pengaplikasian Augmented Reality pada Modul Pembelajaran Menggambar Teknik 2 dan CAD menggunakan jenis penelitian pengembangan R\&D (Research and Development ). Waktu penelitian ini dilaksanakan mulai bulan Juni 2019 sampai dengan bulan Agustus 2019. Tempat dilaksanakannya penelitian adalah di Program Studi Pendidikan Teknik Bangunan Fakultas Teknik Universitas Negeri Jakarta. Sasaran penelitian ini adalah seluruh mahasiswa semester genap yang mengambil mata kuliah Menggambar Teknik 2 dan CAD di Program Studi Pendidikan Teknik Bangunan. Instrumen pengumpulan berguna untuk memperoleh data yang dibutuhkan sesuai dengan tujuan penelitian. Instrumen kelayakan menggunakan skala Likert denga alternatif jawaban : sangat baik, baik, cukup, kurang dan sangat kurang. Supaya diperoleh data kuantitatif maka alternatif jawaban diberi skor yakni sangat baik $=5$, baik $=4$, cukup $=3$, kurang $=2$, sangat kurang $=1$. Prosedur dalam pengembangan dalam penelitian ini dimulai dengan Tahap Penelitian dan Pengumpulan Informasi yaitu dimulai dengan studi analisis kebutuhan yang diperlukan untuk mendapatkan data untuk bahan penelitian dan analisis kinerja untuk mendapatkan informasi. Tahap selanjutnya adalah tahap perencanaan yaitu, produk berupa modul dan aplikasi untuk Smartphone Android perlu dilakukan pengujian untuk mengetahui kualitas dan kelayakannya. Subyek penelitian meliputi ahli atau pakar, dosen pengampu mata kuliah Menggambar 
Teknik 2 \& CAD. Produk akan dikonsultasikan kepada dosen pembimbing, pakar/ahli, dosen pengampu mata kuliah Menggambar Teknik 2 \& CAD. Tahap selanjutnya yaitu tahap desain produk yaitu, pengembangan aplikasi ARCAD3D sebagai media pembelajaran Menggambar Teknik 2 dan CAD mengikuti tahapan-tahapan pada model pengembangan Four $D$ (4-D). Berikut adalah tahapan model Four D (4-D) yang disesuaikan dengan penelitian ini.

Teknik pengumpulan data yang digunakan dalam penelitian ini adalah metode kuisioner dan observasi. Teknik analisis data yang dilakukan adalah dengan analisis validasi ahli, yang terdiri dari dua ahli materi dan dua ahli media.

Validasi ahli dilakukan menggunakan Skala Likert. Jawaban dari setiap instrument memiliki tingkatan dari yang sangat positif hingga negative (Sugiyono, 2015). Skor penilaian yang digunakan merupakan penilaian angka dari 1 sampai 5, dimana 1 sebagai nilai negatif dan 5 sebagai nilai positif. Menghitung skor validitas dari hasil penilaian ahli dapat menggunakan rumus dari Purwanto (2010) yang telah dimodifikasi (Sistyarini \& Nurtjahyani, 2017):

Validitas $(V)=\frac{\text { Jumlah skor yang diperoleh }}{\text { Total skor maksimal }} \times 100 \%$

Analisis dilakukan dengan menggabungkan perhitungan validasi gabungan dengan rumus:

$$
\begin{aligned}
& V \text { materi }=\frac{\text { validator } \text { materi } 1+\text { validator materi } 2}{2} \\
& V \text { media }=\frac{\text { validator } \text { media } 1+\text { validator media } 2}{2} \\
& V \text { total }=\frac{V \text { mater } i+V \text { media }}{2}
\end{aligned}
$$

\section{Hasil Penelitian dan Pembahasan}

Produk yang dikembangkan dalam penelitian ini adalah media pembelajaran menggambar tekik 2 dan CAD. Media pembelajaran tersebut dikemas dalam bentuk Modul Pembealajaran Menggambar Teknik 2 dan CAD dan aplikasi ARCAD3D pada Smartphone Android. Media pembelajaran ini menggunakan Augmented Reality dimana pengguna dapat melihat objek tiga dimensi dari gambar pada modul yang menggunakan apliaksi ARCAD3D. Tahap awal untuk membuat media pembelajaran ini yaitu dengan menganalisis kebutuhan. Kegiatan analisis kebutuhan ini adalah memberikan angket kepada mahasiswa sebagai responden yang berisikan media apa yang dibutuhkan dalam pembelajaran Menggambar Teknik 2 dan CAD.

Tahap selanjutnya yaitu mendesain produk yang dikembangkan. Tahap desain produk kegiatannya meliputi penentuan komponen materi yang akan dibuatkan modul dan akan diintegrasikan dengan aplikasi berbasis Augmented Reality, konsep penyampaian dan pengorganisasian materi, perancangan model 3D, pembuatan marker, perancangan AR, pembuatan menu pada aplikasi dan pembuatan modul. Tahap ini akan menghasilkan desain produk awal berupa rancangan media tiga dimensi yang sebelumnya telah dilakukan penyusunan instrumen penilaian produk untuk dijadikan pedoman dalam mendesain produk.

Media yang telah selesai dibuat akan dikonsultasikan dengan dosen pembimbing dan diuji oleh ahli materi dan ahli media. Penentuan ahli media dan ahli materi yang memvalidasi media pembelajaran adalah sesuai dengan arahan dosen pembimbing. Pengujian ini dilakukan untuk memvalidasi produk yang dikembangkan. Dari lembar evaluasi media pembelajaran, peneliti dapat mengetahui kekurangan dari media pembelajaran yang harus diperbaiki. Pada pengujian materi, ahli materi menilai produk dari beberapa aspek, yaitu kelayakan isi, kelayakan penyajian, dan penialaian bahasa. Ahli materi yang menguji produk ini adalah dua orang dosen yaitu M. Aghpin Ramadhan, M.Pd dosen 
Pendidikan Teknik Bangunan Fakultas Teknik Universitas Negeri Jakarta dan Wahli Wardhana, M.Pd dosen Teknik Sipil Fakultas Teknik Universitas Sultan Ageng Tirtayasa. Hasil pengujian dari ahli materi dengan rata persentase $81,8182 \%$ dengan interpretasi sangat baik. Hal ini dapat disimpulkan bahwa secara materi, media pembelajaran ini layak dan sesuai dengan Rencana Pembelajaran Semester Menggambar Teknik 2 dan CAD.

Pada pengujian media pembelajaran, dilakukan oleh dua ahli media yang merupakan dosen Universitas Negeri Jakarta yaitu Dr. Turi Iriani, M.Si dan Prasetyo Wibowo Y, M.Eng. Pengujian media terdiri dari beberapa aspek, yaitu aspek kualitas tampilan, rekayasa perangkat lunak, keterlaksanaan, interface, reusbale, maintanable, compatibility yang digunakan untuk menguji media pembelajaran berupa aplikasi ARCAD3D pada Smartphone Android. Sedangkan untuk Modul Pembelajaran Menggambar Teknik 2 dan CAD yaitu aspek kelayakan kegrafikan. Berdasarkan data hasil penilaian media oleh ahli media dinyatakan layak untuk diterapkan pada kegiatan pembelajaran karena hasil rata-rata persentase sebesar $85,6 \%$ dengan interpretasi sangat baik.

Tabel 1. Hasil Penilaian Ahli Materi dan Ahli Media Untuk Media Pembelajaran

\begin{tabular}{lcccc}
\hline $\begin{array}{c}\text { Media } \\
\text { Pembelajaran }\end{array}$ & $\begin{array}{c}\text { Skor } \\
\text { Max }\end{array}$ & $\begin{array}{c}\text { Skor Ahli } \\
\text { (V1+V2) }\end{array}$ & $\mathbf{\%}$ & Interpretasi \\
\hline $\begin{array}{l}\text { Aplikasi } \\
\text { ARCAD3D }\end{array}$ & 200 & 188 & 94 & Sangat Baik \\
\hline $\begin{array}{l}\text { Modul } \\
\text { Pembelajaran } \\
\text { Menggambar }\end{array}$ & 300 & 240 & 80 & Baik \\
$\begin{array}{l}\text { Teknik 2 dan } \\
\text { CAD }\end{array}$ & & & & \\
\hline Hasil Akhir & $\mathbf{5 0 0}$ & $\mathbf{4 2 8}$ & $\mathbf{8 5 , 6}$ & Sangat Baik \\
\hline
\end{tabular}

Kesimpulan dari beberapa deskripsi diatas dapat ditarik kesimpulan bahwa Augmented Reality layak untuk diaplikasikan pada modul pembelajaran Menggambar Teknik 2 dan CAD dan dapat digunakan oleh dosen maupun mahasiswa dalam proses pembelajaran.
Media pembelajaran dengan Augmented Reality merupakan bentuk animasi 3D dari marker yang dipindai pada modul oleh aplikasi yang dijalankan pada Smartphone Android. Aplikasi ini diberi nama ARCAD3D. Aplikasi yang dapat dipasang pada versi Android mulai dari versi 2.3 Gingerband hingga versi diatasnya dengan file berformat apk. Setiap komponen pada modul disajikan dengan materi yang telah disesuaikan dengan Rencana Pembelajaran Semester (RPS) yang dilengkapi dengan sebuah marker bergambar komponen bangunan tersebut. Marker tersebut dapat dipindai oleh aplikasi untuk menampilkan objek 3D komponen tersebut. Saat membuka aplikasi akan muncul tampilan menu utama yang dapat diakses oleh pengguna untuk masuk ke menu PETUNJUK, UNDUH MODUL, MATERI 3D, KELUAR, dan TENTANG.

\section{Simpulan}

Pengaplikasian Augmented Reality pada Modul Pembelajaran Menggambar Teknik 2 dan CAD setelah melalui beberapa tahapan penelitian, maka dapat disimpulkan Produk yang telah peneliti buat berupa Modul Pembelajaran Menggambar Teknik 2 dan CAD dan aplikasi ARCAD3D untuk smartphone Android. Modul Pembelajaran Menggambar Teknik 2 dan CAD menyajikan materi-materi sesuai dengan materi yang ada pada Rencana Pembelajaran Semester (RPS) yang berjumlah 12 bab. Modul dilengkapi dengan marker pada setiap pembahasan komponen tiga dimensi. Marker tersebut berfungsi agar dapat dideteksi atau dipindai oleh aplikasi ARCAD3D untuk dapat menampilkan objek 3D sesuai dengan bentuk komponen bangunan pada aslinya. Aplikasi ARCAD3D yang berformatkan apk. dapat digunakan pada smartphone Android mulai dari versi 2.3 Gingerband hingga versi diatasnya. Dalam aplikasi ini terdapat 18 (delapan belas) objek 3D yang dapat ditampilkan. Tingkat kelayakan 
media pembelajaran ini dilihat dari penilaian oleh ahli materi dan ahli media. Dari data yang diperoleh nilai kelayakan pada pengujian media pembelajaran oleh materi sebesar $81,8182 \%$, validasi konstruk oleh ahli media 85,6\%. Seluruh data hasil penilaian dari ahli materi dan ahli media menunjukan kategori media pembelajaran yang sangat layak digunakan dalam proses

Menggambar Teknik 2 dan CAD menghasilkan implikasi sebagai berikut : Penerapan Augmented Reality pada Modul Pembelajaran Menggambar Teknik 2 dan CAD dapat membantu mahasiswa untuk meningkatkan daya imajinasi dalam menggambar teknik. Selain menggunakan Augmented Reality untuk dapat meningkatkan daya imajinasi dalam menggambar teknik, dapat juga memanfaatkan teknologi Virtual Environment atau yang biasa dikenal dengan Virtual Reality (VR) yang dapat menggantikan keseluruhan lingkungan nyata dengan lingkungan maya.

Berdasarkan hasil penelitian, maka saran yang dapat peneliti berikan adalah sebaiknya, diadakan penelitian lain dengan menggunakan software yang tidak dibatasi oleh memori, supaya dapat lebih luas dalam memaparkan suatu materi pembelajaran. Selain itu, aplikasi yang dikembangkan dapat dibuat untuk dapat digunakan di semua sistem operasi smartphone selain Android.

Sebaiknya, untuk dapat meningkatkan daya imajinasi dalam menggambar teknik, selain menggunakan media pembelajaran ini, mahasiswa dapat menggunakan media lain seperti fasilitas yang ada pada Google SketchUp yaitu ARPlugin Google SketchUp. Sebaiknya, diadakan penelitian dengan menggunakan Augmented Reality untuk mata kuliah Desain Interior. Bagi mahasiswa atau peserta didik agar dapat memanfaatkan media pembelajaran berupa Modul Pembelajaran Menggambar Teknik 2 dan CAD dan aplikasi ARCAD3D sebagai salah satu sumber belajar untuk dapat belajar mandiri. pembelajaran. Berdasarkan hasil penilaiaian materi dan media oleh para ahli, Augmented Reality layak diaplikasikan pada modul pembelajaran Menggambar Teknik 2 dan CAD dan dapat digunakan sebagai media pembelajaran di Program Studi Pendidikan Teknik Bangunan, Fakultas Teknik, Universitas Negeri Jakarta. Pengaplikasian Augmented Reality pada Modul Pembelajaran

\section{Daftar Pustaka}

Adam, S., Lumenta, A. S. M., \& Robot, J. R. (2014). Implementasi Teknologi Augmented Reality pada Agen Penjualan Rumah.

Akbar, Hasanudin. (2011). Belajar AutoCAD. Jakarta : Erlangga

Azhar Arsyad. (2012). Media Pembelajaran, Raja Grafindo Persada. Jakarta.

Budi, Septi Aji (2016). Teknik Menggambar Teknik . Jurnal Teknik Sipil, 3(1), 111-112.

Dr. Purwanto, M.Pd, Drs. Aristo Rahadi, Drs. Suharto Lasmono, M. P. (2010). Pengembangan Modul (p. 189). p. 189. Jakarta: Pusat Teknologi Informasi dan Komunikasi.

Nasir, M. (2018). Pengaruh Revolusi Industri 4.0 Terhadap Bidang Kehidupan. Bandung : Penerbit ANDI

Nurcahya Agung Sulistya Budi, (2015). "Pengaruh Motivasi, Persepsi Kualitas dan Sikap Konsumen Terhadap Keputusan Pembelian Smartphone Android Samsung (Studi Kasus Pada Mahasiswa Fakultas Ekonomi Universitas Negeri Yogyakarta). http://www.google.com/url?q=http: //eprints.uny.ac.id/26437/1/Nurca hyaAgungSulistya 
Budi_08408144032.pdf\&sa=U\&ved=0ahU KEwiLzpm0tuzJAhUM2SYKHQ5hBbAQ FggFMAA\&usg=AFQjCNFgF518UpD5_ 9qul6lkSt5lzue2gA. Diakses 21 Juni 2019.

Rusdi Susilana \& Cepi Riyana. 2010. Media Pembelajaran hakikat pengembangan, pemanfaatan, dan Penilaian. Wacana Prima. Bandung

Singhal, Manav; Shukla Anupam. (2012). Implementation of Location Based Services in Android Using GPS and Web Services. Retrieved June 20, 2019

from http:/ /ijcsi.org/papers/IJCSI-9-1-2237-242.pdf

Sugiyono. (2015). Metode Penelitian Pendidikan Pendekatan Kuantitatif Kualitatif dan R\&D (22nd ed.). Bandung: Alfabeta. 